\title{
Distribution of Pasteurella multocida B:2 in the Respiratory, Gastrointestinal and Urinary Tracts of Buffaloes Following Experimental Subcutaneous Inoculation \\ Annas S, Zamri-Saad M*, Abubakar MS, Jesse FFA and Zunita Z
}

Research Centre for Ruminant Diseases, Faculty of Veterinary Medicine, Universiti Putra Malaysia, Malaysia

\begin{abstract}
Pasteurella multocida B:2 causes haemorrhagic septicaemia (HS) in cattle and buffalo, leading to acute death of many animals, usually in the form of outbreaks. HS occurs especially in Asia and Africa, leading to devastating loss of animals and economics. The involvement of respiratory tract as the route of infection and transmission has been well established. The present study describes the distribution of $P$. multocida $\mathrm{B}: 2$ using bacteriological isolations in the respiratory, gastrointestinal and urinary tracts of buffalo calves following different dosages of subcutaneous exposure to live wild-type P. multocida B:2. Nine buffalo calves were divided into 3 groups before calves of Group 1 were inoculated subcutaneously with $10^{9} \mathrm{cfu} / \mathrm{ml}$ of live wild-type $P$. multocida B:2. Calves of Group 2 were similarly inoculated with $10^{5} \mathrm{cfu} / \mathrm{ml}$ while calves of Group 3 were exposed to PBS. All calves of Group 1 were euthanised between 6 and $12 \mathrm{~h}$ post-infection, while calves Group 2 were euthanized between 24 and $48 \mathrm{~h}$ post-infection. $P$. multocida B:2 was isolated from the lungs, liver, deodenum, rectum, urinary bladder swabs and the urine of all infected calves of Groups 1 and 2. Bacterial concentration varied between the organs with the lungs showed significantly $(p<0.05)$ higher concentration than other tracts. Nevertheless, duodenum, colon, liver and urinary bladder of infected calves showed considerably high concentrations of $P$. multocida B: 2 . Both infected groups showed similar concentrations of $P$. multocida B:2 in the respiratory, gastrointestinal and urinary tracts. Isolation and detection of $P$. multocida B:2 in the gastrointestinal and urinary tracts of infected calves re-emphasize the role of these tracts in transmission of haemorrhagic septicaemia and aid in understanding the terminal stage of bacteraemia in HS.
\end{abstract}

Keywords: Pasteurella multocida B:2; Distribution; Respiratory; Gastrointestinal; Urinary tract; Buffalo

\section{Introduction}

Pasteurella multocida is a Gram-negative bacterium known to be the agent for important diseases in animals. Pasteurella multocida is basically classified based on serogroups (A,B,D,E and F) and somatic serovars (1 to 16). Different serogroups and/or serovars are known to cause different diseases in different species of animals, for example haemorrhagic septicaemia in ruminants (serotypes B:2 or E:2), atrophic rhinitis in pigs (serogroups $\mathrm{A}$ and D) and fowl cholera in poultry (serotypes A:1, A:3 and A:4) [1-3]. Haemorrhagic septicaemia (HS) in ruminants leads to severe economic losses from high mortality among buffaloes in most tropical countries [1,4]. Typical clinical signs of HS in ruminants include severe depression, pyrexia, submandibular oedema, dyspnea, recumbency and death [5]. The agent is believed to gain entry into the host through inhalation and ingestion $[1,6]$ resulting in septicaemia and multiple-organ haemorrhages.

Following entrance, septicaemia develops leading to peracute disease, which is the characteristic of natural outbreaks of HS. This has been associated with bacterial distribution in various organs. Most scientific authors speculated but without experimental proof that transmission of HS via gastrointestinal and/or urinary tracts is possible. Nevertheless, recent experiments concluded that the involvement of gastrointestinal and urinary tracts is highly possible, when $P$. multocida B:2 was isolated and detected in most parts of the gastrointestinal tract of orally inoculated as well as carrier buffaloes [6,7]. With the knowledge that transmission is highly possible via the gastrointestinal and urinary tracts, it is wise to determine the bacterial distribution and compare with the respiratory tract, which has been proven to play a major role in transmission of HS. Therefore, the present study describes lesions and bacterial distribution in various organs of the respiratory, gastrointestinal as well as urinary tracts following experimental exposure of buffalo calves to wild-type P. multocida B:2.

\section{Materials and Methods}

\section{Experimental animals}

Nine 8-month old clinically healthy buffalo calves from a farm with no history of outbreak or vaccination against HS were selected. Upon arrival to the experimental house, the calves were acclimatized for 5 days when anthelmintic (Ivomectin, Suffolk, UK) was administered subcutaneously at the rate of $0.2 \mathrm{mg} / \mathrm{kg}$ body weight. Concurrently, deep nasal swabs were collected weekly and examined for the presence of $P$. multocida $\mathrm{B}: 2$ by bacterial isolation and polymerase chain reaction to ensure that the calves were free from $P$. multocida $\mathrm{B}: 2$ prior to the start of the experiment [7]. Blood sera were also collected to ensure that the calves had low specific antibody titre using the enzyme-linked immunosorbent assay (ELISA) [7]. The calves were fed cut grass and supplemented with palm kernel based pellets at the rate of $400 \mathrm{~g} / \mathrm{calf} /$ day. Drinking water was available ad libitum. Access to veterinary care was available at all times and the well-being of the calves was assessed regularly.

*Corresponding author: Zamri-Saad M, Research Centre for Ruminant Diseases, Faculty of Veterinary Medicine, Universiti Putra Malaysia, Malaysia, Tel: +603 8609 3453; E-mail: mzamri@upm.edu.my

Received April 17, 2014; Accepted June 27, 2014; Published June 30, 2014

Citation: Annas S, Zamri-Saad M, Abubakar MS, Jesse FFA, Zunita Z (2014) Distribution of Pasteurella multocida B:2 in the Respiratory, Gastrointestinal and Urinary Tracts of Buffaloes Following Experimental Subcutaneous Inoculation. J Veterinar Sci Technol 5: 177. doi:10.4172/2157-7579.1000177

Copyright: $\odot 2014$ Annas S, et al. This is an open-access article distributed under the terms of the Creative Commons Attribution License, which permits unrestricted use, distribution, and reproduction in any medium, provided the original author and source are credited. 
Citation: Annas S, Zamri-Saad M, Abubakar MS, Jesse FFA, Zunita Z (2014) Distribution of Pasteurella multocida B:2 in the Respiratory, Gastrointestinal and Urinary Tracts of Buffaloes Following Experimental Subcutaneous Inoculation. J Veterinar Sci Technol 5: 177. doi:10.4172/21577579.1000177

Page 2 of 6

\section{Bacterial strain}

A stock culture of $P$. multocida serotype B:2, which was isolated earlier from an outbreak of HS was used [8]. The organism was cultured on blood agar at $37^{\circ} \mathrm{C}$ for $24 \mathrm{~h}$ before the brain-heart infusion broth was seeded with four uniformly sized colonies and incubated at $37^{\circ} \mathrm{C}$ with shaking at $150 \mathrm{rpm}$ for $18 \mathrm{~h}$. The bacterial concentration was determined using serial dilution method described previously [9] to produce an estimated infection dose of $1.0 \times 10^{9}$ and $1.0 \times 10^{5}$ colony forming unit (cfu)/ml of P. multocida B:2.

\section{Experimental design}

The calves were divided into three groups and kept in individual pen, and each group was kept separated. At the start of the experiment, all calves of Group 1 were challenged subcutaneously with $5 \mathrm{ml}$ of the inoculums containing $1.0 \times 10^{9} \mathrm{cfu} / \mathrm{ml}$ of live wild-type $P$. multocida $\mathrm{B}: 2$ [10]. Calves of Group 2 were similarly challenged with $1.0 \times 10^{5} \mathrm{cfu} /$ $\mathrm{ml}$ of wild-type $P$. multocida B:2. The calves of Group 3 were similarly exposed to sterile phosphate buffered saline (PBS) and remained as control unchallenged. All calves were observed for signs of HS. The Animal Care and Use Committee of Universiti Putra Malaysia approved the experimental procedures (Approval Number 12R148).

At the end of day three post-infection, surviving calves were euthanised and post-mortem examination was carried out immediately. At necropsy, attention was focused on the lesions along the respiratory, gastrointestinal and urinary tracts. The gross lesions were described following examinations by visualization and palpation. Samples of lung, various sections of gastrointestinal tract, and sections of urinary tract were collected for bacteriological examinations. Rectal and urinary bladder swabs, and urine were collected for bacterial isolation.

\section{Sample processing}

Samples from each lobe of the lung, sections of small and large intestines, and sections of urinary tract were collected in triplicate from each calf. The sample sites for the gastrointestinal tracts included liver, rumen, reticulum, omasum, abomasum, duodenum, jejunum, ileum, cecum, colon and rectum while for the urinary tract were kidney and urinary bladder. At necropsy, different personnel sampled the tracts simultaneously. This was done at separate sampling areas to ensure minimal contamination between the samples. The bacterial concentrations in each tissue were determined using the method previously described [11] with slight modification. Briefly, each tissue was weighed, and subsequently homogenized in sterile PBS $(5 \mathrm{ml} / \mathrm{g})$ using a tissue homogenizer. The resulted aliquot was then diluted 10 -folds to $10^{-8}$. Aliquot $(100 \mu \mathrm{l})$ of each dilution was then applied onto blood agar plates and incubated at $37^{\circ} \mathrm{C}$ for $18 \mathrm{~h}$. Viable counts of $P$. multocida $\mathrm{B}: 2$ were determined by their colony morphology [12], confirmed by PCR [7] and expressed as cfu/g of tissue [11].

\section{Statistical analysis}

Data were analyzed using descriptive statistics. One-way ANOVA was used to compare the concentrations of P. multocida B:2 in different segments of the respiratory, gastrointestinal and urinary tracts. Independent $t$-test was used to compare the concentrations of $P$. multocida B:2 in organs between Groups 1 and 2. Data were expressed as mean \pm standard error of the mean (SEM) All statistical analyses were done using SPSS version 21.

\section{Results}

Following subcutaneous inoculation of $P$. multocida B:2, all calves of Group 1 were euthanised between 6 and $12 \mathrm{~h}$ post-infection, where a calf was euthanised at $6 \mathrm{~h}$, another at $10 \mathrm{~h}$ and the third at $12 \mathrm{~h}$ postinoculation. On the other hand, calves of Group 2 were euthanized between 24 and $48 \mathrm{~h}$ post-infection, where 2 calves were euthanized at $24 \mathrm{~h}$ and another at $48 \mathrm{~h}$ post-infection. The affected calves from both groups appeared depressed and dull, pyretic with nasal discharge, and showed signs of anorexia, dyspnea, diarrhea, and recumbency before being euthanised. Calves of Group 3, however, survived the experiment and were euthanised on day three post-exposure.

The buffalo calves of Groups 1 and 2 showed similar typical lesions of HS. The mucous membranes were congested, particularly the conjunctiva. Multifocal subcutaneous haemorrhages were observed in all affected calves but none showed the submandibular oedema. The entire respiratory tract was severely congested, with the presence of large amount of frothy exudate in the lumen of trachea, bronchi and bronchioles. The lungs were severely congested and oedematous with multifocal areas of consolidation.

There were moderate to severe congestion and haemorrhages along the gastrointestinal tract. Severe congestion and haemorrhages were observed in the abomasum (Figure 1A). The wall of small intestines was thickened with moderate to severe congestion and haemorrhage. The ileal content appeared mucopurulent while the wall was thickened and corrugated (Figure 1B). The large intestine showed moderate to
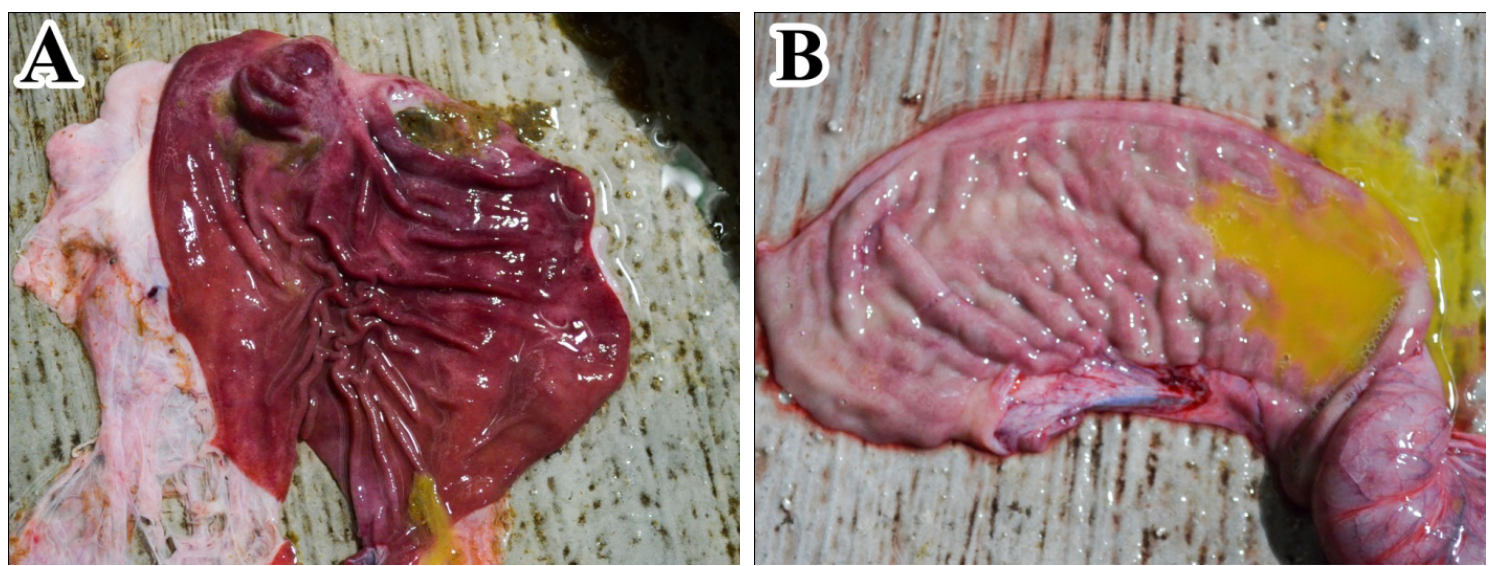

Figure 1: (A) Severely congested abomasal mucosa and (B) moderately congested ileal mucosa. Note the clear corrugation of the ileal mucosa with mucoid content. 
Citation: Annas S, Zamri-Saad M, Abubakar MS, Jesse FFA, Zunita Z (2014) Distribution of Pasteurella multocida B:2 in the Respiratory, Gastrointestinal and Urinary Tracts of Buffaloes Following Experimental Subcutaneous Inoculation. J Veterinar Sci Technol 5: 177. doi:10.4172/21577579.1000177

Page 3 of 6

severe congestion and haemorrhage with varying degrees of thickening and corrugation of the wall. The cecum and the colon were slightly thickened with mucopurulent content. The rectum showed multifocal to diffuse congestion and petechial haemorrhages with moderate to severe thickening. The kidneys were severely congested while the urinary bladders were moderately congested with haemorrhages. One of the affected calves from Group 1 had haematuria.

P. multocida B:2 was isolated from the lungs, gastrointestinal tract, kidneys and urinary bladder of all calves of Groups 1 and 2. The same organism was also isolated from the rectal and urinary bladder swabs of all calves of Groups 1 and 2, and from the urine of one of the calves of Group 1. Pasteurella multocida B:2 was present in significantly $(\mathrm{p}<0.05)$ higher concentrations in most of the lung lobes than in the gastrointestinal and urinary tracts of Group 1 (Figure 2) and Group 2 (Figure 3). Within the gastrointestinal tract, the liver had significantly $(\mathrm{p}<0.05)$ higher concentration of P. multocida B:2 (Figures 2 and 3). The concentrations of $P$. multocida B:2 in the small intestines, particularly

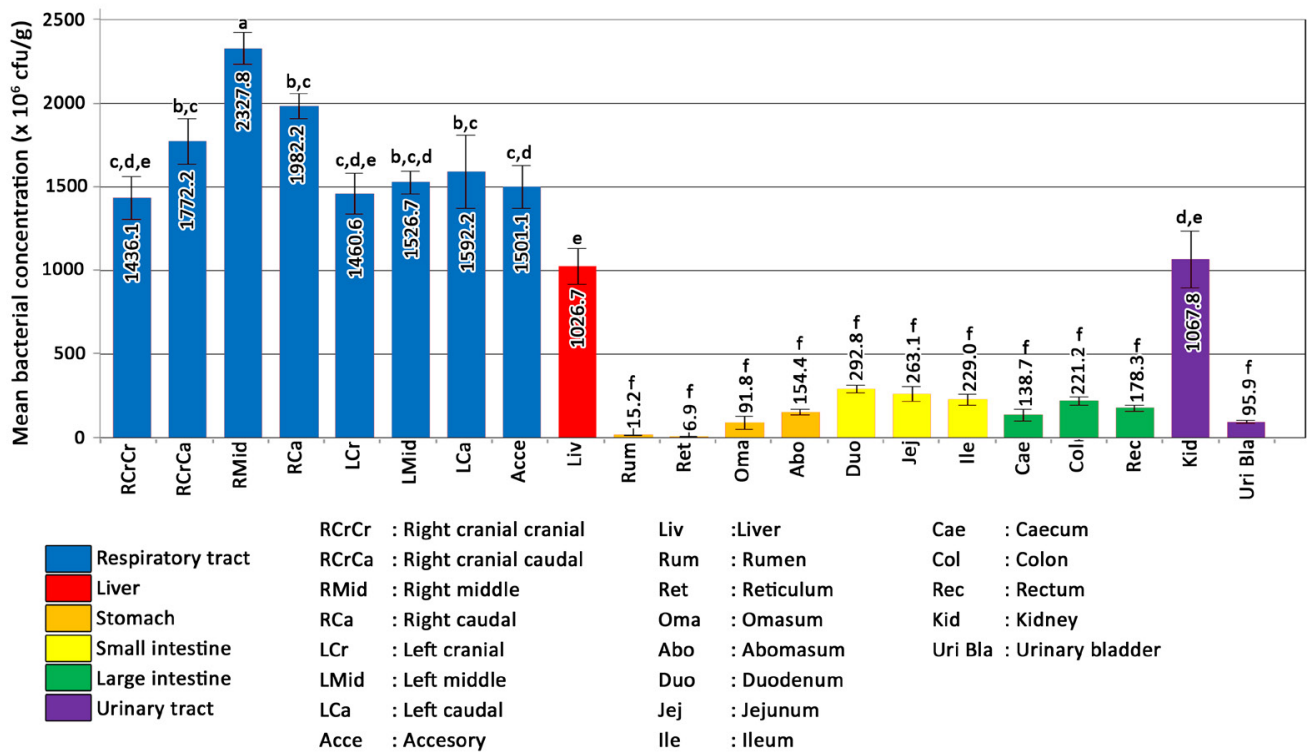

a,b,c,d,e,f Different superscripts indicate significant difference $(p<0.05)$

Figure 2: Average ( \pm SEM) concentration of Pasteurella multocida B:2 in different parts of the respiratory, gastrointestinal and urinary tracts of Group 1 following experimental exposure

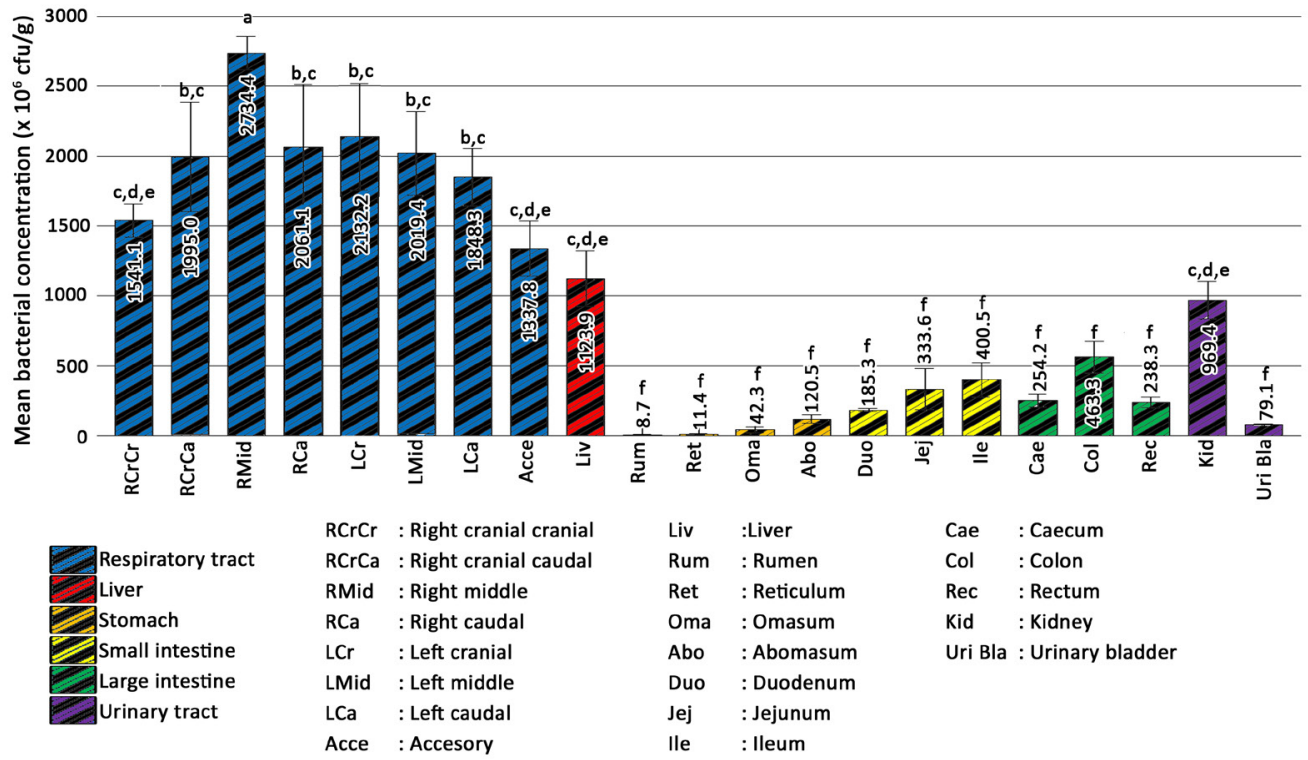

$a, b, c, d, e, f$ Different superscripts indicate significant difference $(p<0.05)$

Figure 3: Average ( \pm SEM) concentration of Pasteurella multocida B:2 in different parts of the respiratory, gastrointestinal and urinary tracts of Group 2 following experimental exposure. 
Citation: Annas S, Zamri-Saad M, Abubakar MS, Jesse FFA, Zunita Z (2014) Distribution of Pasteurella multocida B:2 in the Respiratory, Gastrointestinal and Urinary Tracts of Buffaloes Following Experimental Subcutaneous Inoculation. J Veterinar Sci Technol 5: 177. doi:10.4172/21577579.1000177

Page 4 of 6

in the duodenum, were significantly $(\mathrm{p}<0.05)$ higher than the stomachs and the large intestines of Group 1 (Figure 4). On the other hand, the large intestine, particularly colon of Group 2 showed significantly $(\mathrm{p}<0.05)$ higher concentration of $P$. multocida $\mathrm{B}: 2$ compared to the stomachs and the small intestines. Similarly, the kidneys of both Groups 1 and 2 had significantly $(\mathrm{p}<0.05)$ higher concentration of bacteria than the gastrointestinal tract, except for the liver (Figures 2 and 3 ).

Comparisons of $P$. multocida $\mathrm{B}: 2$ concentration in different organs between Group 1 and Group 2 revealed no significant $(\mathrm{P}>0.05)$ different in most organs, except for the right middle lung lobe, rumen, duodenum and colon (Figures 3,5 and 6).

\section{Discussion}

The present study reports the distribution of $P$. multocida $\mathrm{B}: 2$ in the respiratory, gastrointestinal and urinary tracts following subcutaneous inoculation of different dosages of $P$. multocida B:2. All infected buffalo calves showed typical signs of HS, which included depression, dullness, anorexia, pyrexia, dyspnea, nasal discharge and recumbency. Death occurred peracutely (between 6 and $12 \mathrm{~h}$ post-infection) in Group 1 , and acutely (24 and $48 \mathrm{~h}$ post-inoculation) in Group 2. Similar clinical signs were previously reported in both naturally [13-15] and experimentally infected animals $[10,15,16]$. However, brisket or submandibular oedema was not observed.

In general, the respiratory organs were observed to have significantly higher concentration of $P$. multocida $\mathrm{B}: 2$ compared to the gastrointestinal and urinary organs, except for liver and the urinary bladder in both infected groups. These findings are in agreement with the earlier finding that $P$. multocida has high affinity for the lungs

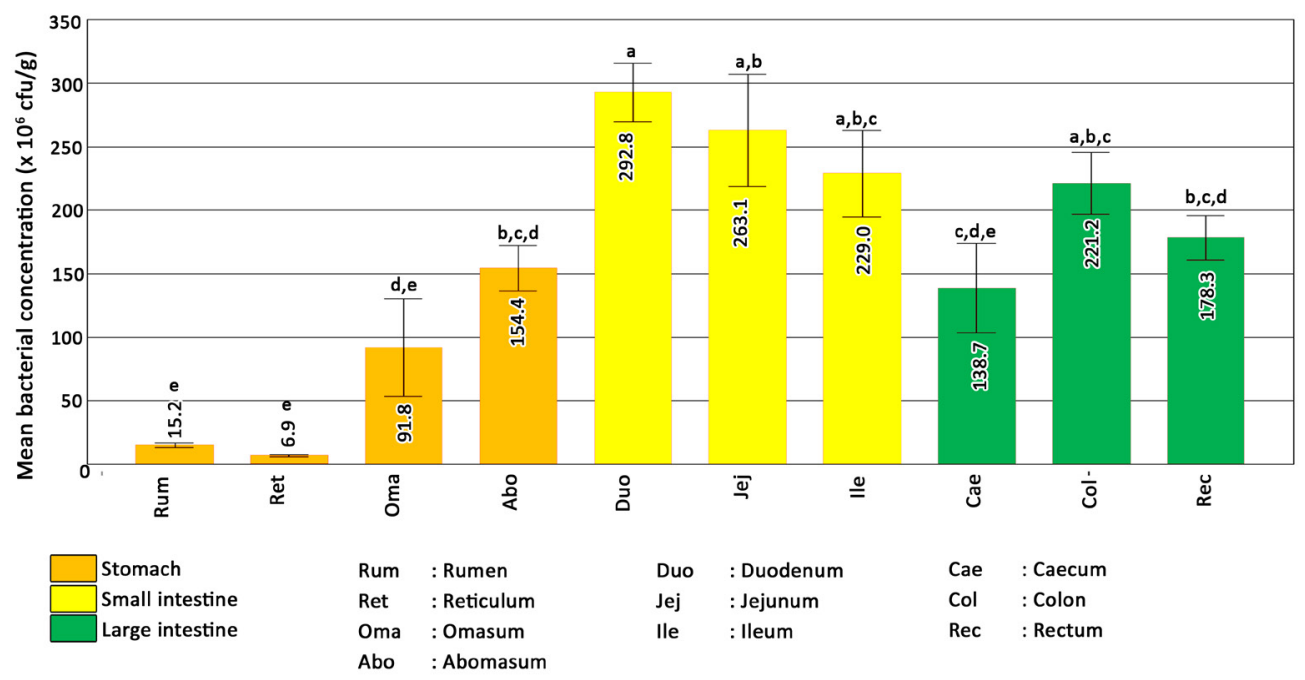

${ }^{a, b, c}$ Different superscripts indicate significant difference $(p<0.05)$

Figure 4: Average ( \pm SEM) comparison between concentrations of Pasteurella multocida B:2 in different parts of the luminal gastrointestinal tracts of Group 1 following experimental exposure.

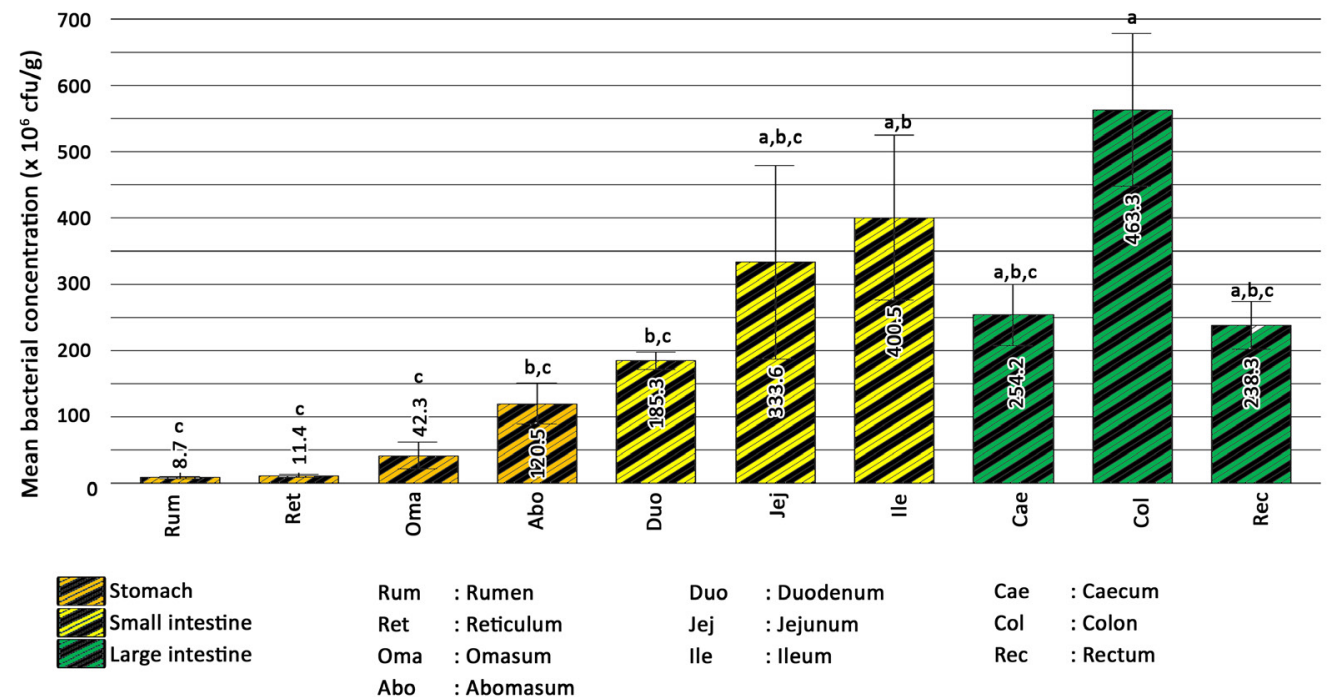

a,b,c,d,e Different superscripts indicate significant difference $(p<0.05)$

Figure 5: Average ( \pm SEM) comparison between concentrations of Pasteurella multocida B:2 in different parts of the luminal gastrointestinal tracts of Group 2 following experimental exposure. 
Citation: Annas S, Zamri-Saad M, Abubakar MS, Jesse FFA, Zunita Z (2014) Distribution of Pasteurella multocida B:2 in the Respiratory, Gastrointestinal and Urinary Tracts of Buffaloes Following Experimental Subcutaneous Inoculation. J Veterinar Sci Technol 5: 177. doi:10.4172/21577579.1000177

Page 5 of 6

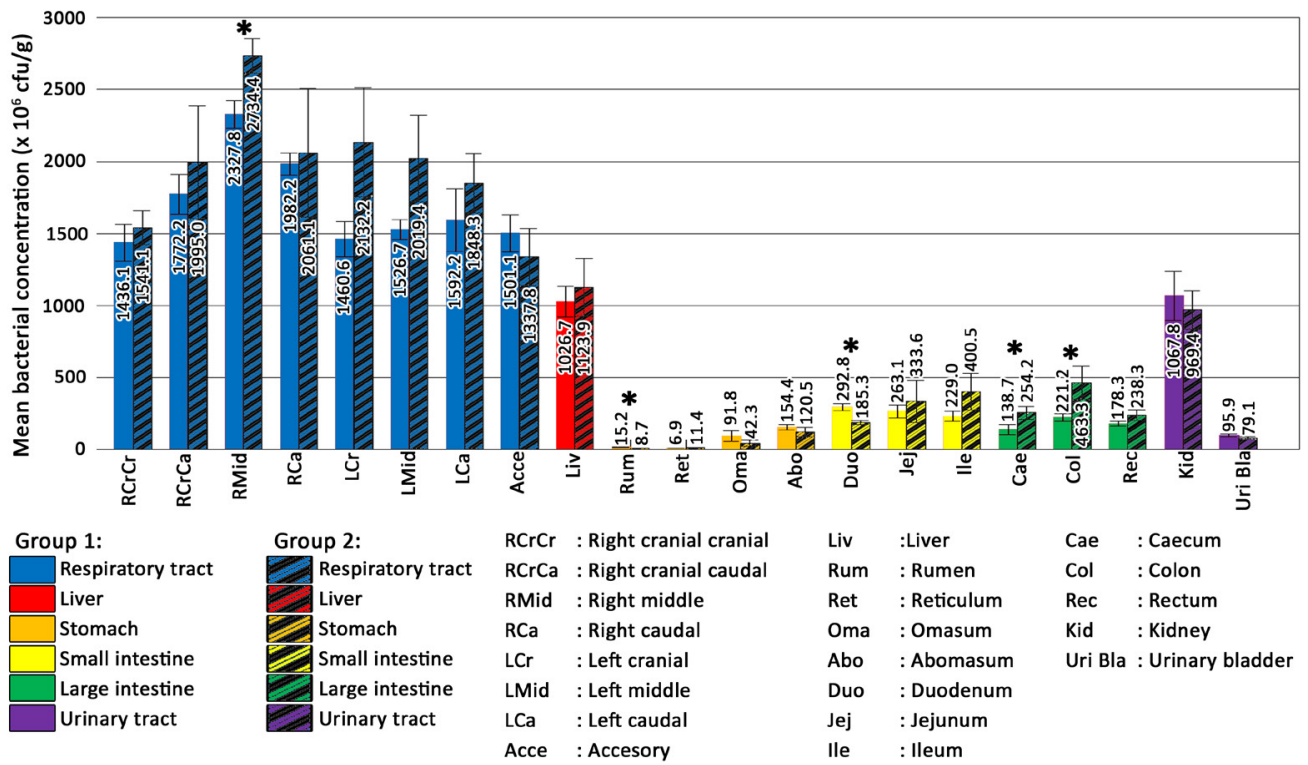

indicates significant difference $(p<0.05)$

Figure 6: Mean ( \pm SEM) comparison between concentration of $P$. multocida B:2 in different parts of respiratory, gastrointestinal and urinary tracts of buffalo calves of Group 1 and Group 2 following experimental exposure.

$[17,18]$. The anatomical location of tracheal bifurcation and hilum of pulmonary vessel explain the high concentration of bacteria in the right middle lobe [19].

Although the respiratory tract was found to harbour high concentrations of $P$. multocida B:2, the gastrointestinal organs, particularly the liver, duodenum and colon were also found to have significantly high concentrations of $P$. multocida B:2. The liver, being a huge and compact organ, holds large amount of blood that contributes to the high concentration of bacteria $[20,21]$. Furthermore, the bacterial flora in the gastrointestinal tract compete and suppress the growth of P. multocida B:2 within the gastrointestinal tract [22-25]. The small intestine particularly the duodenum and colon showed significantly high concentration of $P$. multocida $\mathrm{B}: 2$, suggesting the better affinity compared to other parts of the intestine. The considerably high concentration of $P$. multocida $\mathrm{B}: 2$ in the gastrointestinal tract, especially in the most distal part of the gastrointestinal tract, coupled with isolation of $P$. multocida B:2 from all of the rectal swabs highly supports the findings previously observed [7]. This present study suggests that HS transmission via feces mainly originates from the small and large intestines.

The urinary tract particularly the kidneys and bladder also showed high concentrations of $P$. multocida B:2. The high bacterial concentration and positive isolations from the urine and urinary bladder swabs suggest the involvement of urinary tract in acute HS. Thus, it is highly possible that, before death, the peracute and acutely affected animals shed P. multocida B:2 in the urine, contaminating the environment and subsequently transmitting the organism to other susceptible animals. However, carrier animals do not harbour the organism in the kidneys [7].

Following inoculation of buffalo calves with different dosage of $P$. multocida $\mathrm{B}: 2$, this study concludes that the pattern of distribution of $P$. multocida $\mathrm{B}: 2$ in peracute and acute infections remains the same, where the respiratory organs seem to be the preferred sites for P. multocida
B:2. Furthermore, not many organs showed significant differences in the concentrations of $P$. multocida $\mathrm{B}: 2$ between the group infected with high and low dose of P. multocida B:2. Since septicaemia is known to be the terminal stage in HS [5], once septicaemia developed, the outcome in term of bacterial distribution and concentration would relatively remain the same regardless of the initial infective dosage.

\section{Conclusions}

This paper describes and compares the distribution of $P$. multocida B:2 following experimental infection with different dosages of $P$. multocida B:2 in buffalo calves. It involved many other major body systems, not only the respiratory tract that was previously believed. Comparison of $P$. multocida B:2 concentration in different organs provides clue to the importance of the different organs and/or tracts in development and transmission of HS in peracute and acutely affected animals

\section{Acknowledgements}

This study was financially supported ERGS grant of the Ministry of Higher Education Malaysia.

\section{References}

1. Benkirane A, De Alwis MCL (2002) Haemorrhagic septicaemia, its significance, prevention and control in Asia. Vet Med - Czech 47: 234-240.

2. Varte Z, Dutta TK, Roychoudhury P, Begum J, Chandra R (2014) Isolation, identification, characterization and antibiogram of Pasteurella multocida isolated from pigs in Mizoram with special reference to progressive atrophic rhinitis. Vet World 7: 95-99.

3. Tabatabai LB, Zehr ES (2004) Identification of five outer membrane-associated proteins among cross-protective factor proteins of Pasteurella multocida. Infect Immun 72: 1195-1198.

4. de Alwis MC, Wijewardana TG, Gomis Al, Vipulasiri AA (1990) Persistence of the carrier status in haemorrhagic septicaemia (Pasteurella multocida serotype 6:B infection) in buffaloes. Trop Anim Health Prod 22: 185-194.

5. Horadagoda NU, Hodgson JC, Moon GM, Wijewardana TG, Eckersall PD (2001) Role of endotoxin in the pathogenesis of haemorrhagic septicaemia in the buffalo. Microb Pathog 30: 171-178. 
Citation: Annas S, Zamri-Saad M, Abubakar MS, Jesse FFA, Zunita Z (2014) Distribution of Pasteurella multocida B:2 in the Respiratory, Gastrointestinal and Urinary Tracts of Buffaloes Following Experimental Subcutaneous Inoculation. J Veterinar Sci Technol 5: 177. doi:10.4172/21577579.1000177

Page 6 of 6

6. Abubakar MS, Zamri-Saad M (2011) Clinico-pathological changes in buffalo calves following oral exposure to Pasteurella multocida B:2. J Basic Appl Pathol 4: $130-135$.

7. Annas S, Zamri-Saad M, Jesse FF, Zunita, Z (2014) New sites of localisation of Pasteurella multocida $B$ : 2 in buffalo surviving experimental haemorrhagic septicaemia. BMC Veterinary Research 10: 88

8. Zamri-Saad M, Ernie ZA, Sabri MY (2006) Protective effect following intranasal exposure of goats to live Pasteurella multocida B:2. Trop Anim Health Prod 38 : $541-546$

9. Alcamo IE (1997) Fundamental of Microbiology (5th edn), Addison Wesley Longman, Menlo Park, California.

10. Zamri-Saad M, Shafarin MS (2007) Response of goats to the different routes of infection by Pasteurella multocida B:2. J Anim Vet Adv 6: 340-343.

11. Wang N, Strugnell R, Wijburg O, Brodnicki T (2011) Measuring bacterial load and immune responses in mice infected with Listeria monocytogenes. J Vis Exp.

12. De Alwis, MCL (1999) Haemorrhagic septicaemia, Australian Centre for International Agricultural Research (ACIAR) Monograph 57, ACIAR Canberra, Australia.

13. Abubakar MS, Zamri-Saad M, Jasni S (2013) Ultrastructural changes and bacterial localization in buffalo calves following oral exposure to Pasteurella multocida B:2. Pak Vet J 33: 101-106.

14. Dagleish MP, Finlayson J, Bayne C, MacDonald S, Sales J, et al. (2010) Characterization and time course of pulmonary lesions in calves after intratracheal infection with Pasteurella multocida A:3. J Comp Pathol 142: 157 169

15. Khan A, Saleemi MK, Khan MZ, Gul ST, Irfan M, et al. (2011) Hemorrhagic septicemia in buffalo (Bubalus bubalis) calves under sub-tropical conditions in Pakistan. Pak J Zool 43: 295-302.

16. Khin MN, Zamri-Saad M, Noordin MM (2010) Pathological changes in the lungs of calves following intratracheal exposure to Pasteurella multocida B:2. Pertanika J Trop Agri Sci 33: 113-117.

17. Letellier A, Dubreuil D, Roy G, Fairbrother JM, Jacques M (1991) Determination of affinity of Pasteurella multocida isolates for porcine respiratory tract mucus and partial characterization of the receptors. Am J Vet Res 52: 34-39.

18. Shafarin MS, Zamri-Saad M, Khairani BS, Saharee AA (2009) Pathologica changes in the respiratory tract of goats infected by Pasteurella multocida B:2. J Comp Pathol 140: 194-197.

19. Oliveira FS, Borges EM, Machado MRF, Canola JC, Ribeiro AACM (2001) Anatomicosurgical arterial segmentation of the cat lungs (Felis catus domesticus, L., 1758). Braz J Vet Res Anim Sci 38: 253-257.

20. Reviere JE, Papich MG (2009) In: Veterinary Pharmacology and Therapeutics. (9th edn) Wiley-Blackwell, Ames, lowa.

21. Mitra V, Metcalf $J$ (2011) Functional anatomy and blood supply of the liver Anaest Inten Care Med 13: 52-53.

22. Dethlefsen L, McFall-Ngai M, Relman DA (2007) An ecological and evolutionary perspective on human-microbe mutualism and disease. Nature 449: 811-818.

23. Tappenden KA, Deutsch AS (2007) The physiological relevance of the intestinal microbiota--contributions to human health. J Am Coll Nutr 26: 679S-83S.

24. Stecher B, Hardt WD (2008) The role of microbiota in infectious disease Trends Microbiol 16: 107-114.

25. Turnbaugh PJ, Gordon JI (2009) The core gut microbiome, energy balance and obesity. J Physiol 587: 4153-4158. 